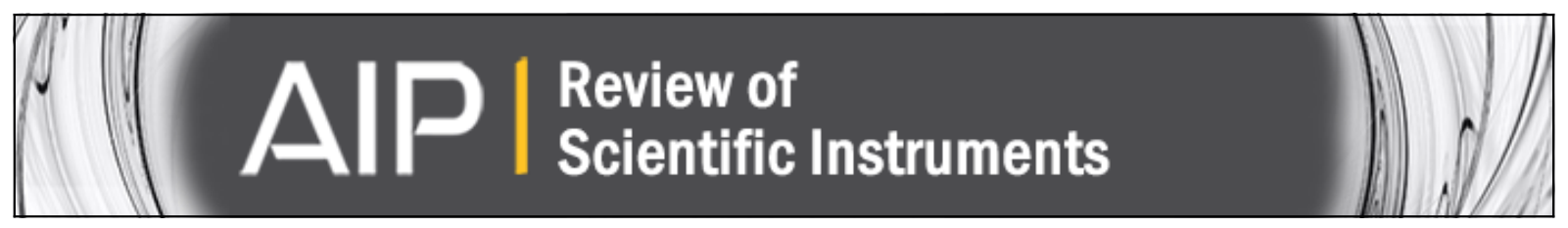

\title{
Ultrafast $x$-ray photoelectron spectroscopy in the microsecond time domain
}

O. Höfert, C. Gleichweit, H.-P. Steinrück, and C. Papp

Citation: Review of Scientific Instruments 84, 093103 (2013); doi: 10.1063/1.4821496

View online: http://dx.doi.org/10.1063/1.4821496

View Table of Contents: http://scitation.aip.org/content/aip/journal/rsi/84/9?ver=pdfcov

Published by the AIP Publishing

\section{Articles you may be interested in}

Light-induced changes in an alkali metal atomic vapor cell coating studied by X-ray photoelectron spectroscopy J. Appl. Phys. 114, 094513 (2013); 10.1063/1.4819235

Mechanism of $\mathrm{CO}$ oxidation reaction on O-covered $\mathrm{Pd}(111)$ surfaces studied with fast x-ray photoelectron spectroscopy: Change of reaction path accompanying phase transition of $\mathrm{O}$ domains

J. Chem. Phys. 124, 224712 (2006); 10.1063/1.2205856

Kinetics of the $\mathrm{CO}$ oxidation reaction on $\mathrm{Pt}(111)$ studied by in situ high-resolution $\mathrm{x}$-ray photoelectron spectroscopy

J. Chem. Phys. 120, 7113 (2004); 10.1063/1.1669378

X-ray photoelectron spectroscopy of nitromethane adsorption products on $\mathrm{Si}(100)$ : A model for $\mathrm{N}$ 1s core-level shifts in silicon oxynitride films

J. Appl. Phys. 95, 1963 (2004); 10.1063/1.1639951

Kinetic parameters of $\mathrm{CO}$ adsorbed on $\mathrm{Pt}(111)$ studied by in situ high resolution $\mathrm{x}$-ray photoelectron spectroscopy

J. Chem. Phys. 117, 10852 (2002); 10.1063/1.1522405

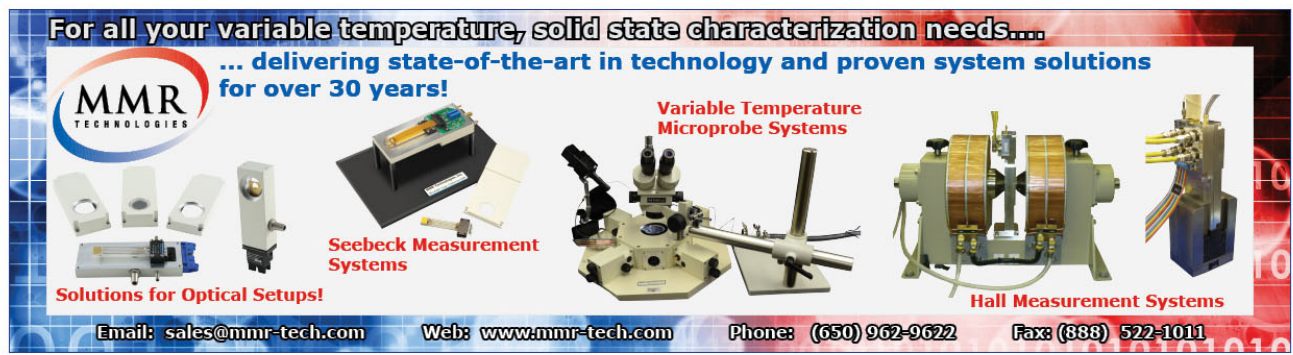


Ultrafast x-ray photoelectron spectroscopy in the microsecond time domain

\author{
O. Höfert, C. Gleichweit, H.-P. Steinrück, and C. Papp ${ }^{\text {a) }}$ \\ Lehrstuhl für Physikalische Chemie II, Universität Erlangen-Nürnberg, Egerlandstr. 3, \\ 91058 Erlangen, Germany
}

(Received 3 August 2013; accepted 2 September 2013; published online 24 September 2013)

\begin{abstract}
We introduce a new approach for ultrafast in situ high-resolution X-ray photoelectron spectroscopy (XPS) to study surface processes and reaction kinetics on the microsecond timescale. The main idea is to follow the intensity at a fixed binding energy using a commercial 7 channeltron electron analyzer with a modified signal processing setup. This concept allows for flexible switching between measuring conventional XP spectra and ultrafast XPS. The experimental modifications are described in detail. As an example, we present measurements for the adsorption and desorption of $\mathrm{CO}$ on $\mathrm{Pt}(111)$, performed at the synchrotron radiation facility BESSY II, with a time resolution of $500 \mu \mathrm{s}$. Due to the ultrafast measurements, we are able to follow adsorption and desorption in situ at pressures of $2 \times 10^{-6}$ mbar and temperatures up to $500 \mathrm{~K}$. The data are consistently analyzed using a simple model in line with data obtained with conventional fast XPS at temperatures below $460 \mathrm{~K}$. Technically, our new approach allows measurement on even shorter timescales, down to $20 \mu \mathrm{s}$. (C) 2013 AIP Publishing LLC. [http://dx.doi.org/10.1063/1.4821496]
\end{abstract}

\section{INTRODUCTION}

Photoelectron spectroscopy has benefitted strongly from the improvements of synchrotron radiation sources. ${ }^{1}$ Especially the high flux and tunable energy allow for using spectroscopic methods such as X-ray photoelectron spectroscopy (XPS) as an in situ measuring tool for determining the surface composition. ${ }^{2}$ Thereby, not only a much better energy resolution but also much shorter data acquisition times than in typical lab experiments were achieved. ${ }^{3}$ Using laboratory $\mathrm{X}$-ray sources, the typical measuring times in the order of several minutes up to hours allow only for a very limited picture of time-dependent changes occurring on a surface. When using synchrotron radiation, the time resolution is significantly improved, such that high-resolution XP spectra can be taken in a few seconds. ${ }^{4}$ With this improvement it became possible to study time-dependent surface processes in situ, i.e., to follow adsorption as function of time or reactions as function of temperature. This gain in time resolution not only opens the possibility to access the kinetics of surface reactions, ${ }^{5,6}$ but also to greatly improve the output in measurement data per time. On top of that further improvements were achieved by new technological efforts: The development of new detectors and the operation of electron analyzers in the so called snapshot mode enable a time resolution of down to $\sim 100 \mathrm{~ms}$ in the case of analyzers with a CCD camera as detector, while times down to $1 \mathrm{~ms}$ are projected for delay line detectors ${ }^{7}$ and other advanced detector designs. ${ }^{8}$ As examples, we like to mention the detector from Bussat et al. ${ }^{9}$ and the company Omicron (128 channel stripe anode detector). The improved time resolution for XPS, and also for other X-ray based techniques, was used to study, e.g., surface reactions, ${ }^{5,10-13}$ giving insights to reaction intermediates and reaction kinetics, ${ }^{6,14,15}$

\footnotetext{
a) Author to whom correspondence should be addressed. Electronic mail: christian.papp@fau.de
}

the growth of different adsorbate layers, ${ }^{4,16}$ including (metal) oxides, ${ }^{17-19}$ graphene, ${ }^{20,21}$ and small hydrocarbons. ${ }^{21-24}$

In addition to the mentioned applications, which all make use of synchrotron radiation in the "multi-bunch mode," for pump and probe-type experiments with much shorter timescales in the nanosecond regime or below the synchrotron facility must be operated in the single bunch mode, i.e., the pulsed time structure of the synchrotron radiation is made use of Ref. 25. Typical setups for the detection of the electrons are either gated analyzers ${ }^{26,27}$ or time-of-flight analyzers. ${ }^{28}$ In these cases, the incident photon numbers are significantly smaller and thus the detected overall number of electrons is lower. Also the aims of experiments with time resolution down to the few femtosecond range are quite different, leading to information on molecular motion and electron movements, e.g., the photovoltaic effects in the valence bands of semiconductor surfaces. ${ }^{29}$ These type of experiments will not be addressed here, but are listed for the sake of completeness.

Herein, we present a new approach, which still uses the "continuous" flux of synchrotron radiation in the multi-bunch mode, with only minimal losses due to analyzer readout times. Thereby, the accessible temperature range for time-dependent spectroscopic studies of surface reactions can be significantly extended to higher temperatures; e.g., up to $500 \mathrm{~K}$ for $\mathrm{CO}$ on $\mathrm{Pt}(111)$, at low surface coverages of only $\sim 0.1 \mathrm{ML}$ and below. The presented data were collected with a time resolution of $500 \mu \mathrm{s}$, and we extrapolate that for the appropriate adsorption/reaction systems measurements with a time resolution of down to $20 \mu$ s should be possible. $\mathrm{CO}$ adsorption on $\operatorname{Pt}(111)$ has been chosen as model adsorbate, since this system has been well characterized in the literature, in particular also with high-resolution XPS. We study the adsorption and transient desorption of $\mathrm{CO}$ at temperatures between 460 and $500 \mathrm{~K}$, and compare the results to data obtained at lower temperatures with a time resolution of $\sim 4 \mathrm{~s}$. Please note that the 
isothermal adsorption/desorption of $\mathrm{CO}$ on $\mathrm{Pt}(111)$ was up to now only studied up to temperatures of $450 \mathrm{~K}$, as at higher temperatures the desorption is too fast, not allowing the required number of data points before complete desorption. ${ }^{4}$ One specific advantage of the approach proposed here is its high flexibility, since the original electron analyzer setup is conserved, and only commercially available standard components are added, which makes the implementation highly cost effective.

In the following, we will introduce the experimental setup thereafter, the results obtained with the new setup will be presented.

\section{EXPERIMENTAL IMPLEMENTATION}

The experiments were conducted at the beamline U 49/2 PGM-1 at the Helmholtz-Zentrum Berlin in our own transportable UHV apparatus, consisting of two chambers. The preparation chamber houses dosing facilities, sputter gun, and LEED (low energy electron diffraction) optics for surface characterization. In the analyzer chamber, a 7 channeltron hemispherical analyzer (Omicron EA 125 U7 HR) is installed. In the past, this analyzer was routinely operated with acquisition times down to $\sim 1.5 \mathrm{~s}$ for a $6 \mathrm{eV}$ wide energy window. A three stage supersonic molecular beam (SSMB) is attached to the analysis chamber for well-defined gas dosing. The SSMB is controlled by a shutter with opening/closing times of about $\sim 50 \mu$ s for a spot size on the sample of $125 \mu \mathrm{m}$; thus, a controlled time structure is available. A specific additional advantage of using the SSMB is the high local pressure of $2 \times 10^{-6}$ mbar on the surface, while keeping the surrounding pressure in the chamber at $2.6 \times 10^{-8}$ mbar. This is particularly important as an "instant" increase/drop in the pressure by a factor of $\sim 77$ on the sample surface results, when the shutter is opened/closed. For further details on the general setup, we would like to point to Ref. 30.

In the following, we want to introduce the changes of the experimental setup to obtain a higher time resolution. The original operation mode is the so called "swept mode," with a single spectrum acquired in a few seconds. Thereby, the kinetic energy of the detected electrons is swept, so that each channeltron collects electrons at the desired kinetic energy for a certain time (dwell time). The spectra of the individual channeltrons (in our case 7) are added appropriately after acquisition (see Figure 1(a)). In the approach presented here, we use our channeltron detector in the style of the "snapshot" mode of CCD camera detectors. This means that we do not change kinetic energy, but acquire data with a fixed kinetic energy in every channeltron; this approach is schematically sketched in Figure 1(b).

In principle, a whole spectrum is obtained by repeating the experiments with the analyzer set to different kinetic energies. However, if the peaks of the investigated surface species do not shift in binding energy during the observed surface processes this is not necessary, and the information can be derived from measuring at only one kinetic energy. This is the case in our model system (see below).

After this general description, we want to describe the actual layout of the fast XPS experiment in Figure 2 and (a) swept mode - full spectrum:

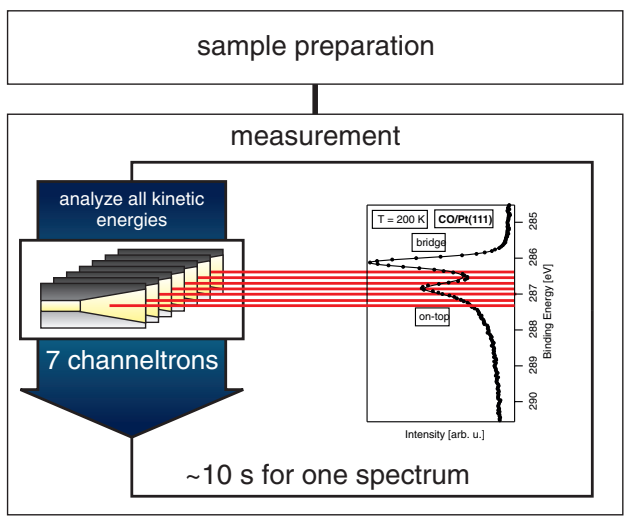

(b)

snapshot mode:

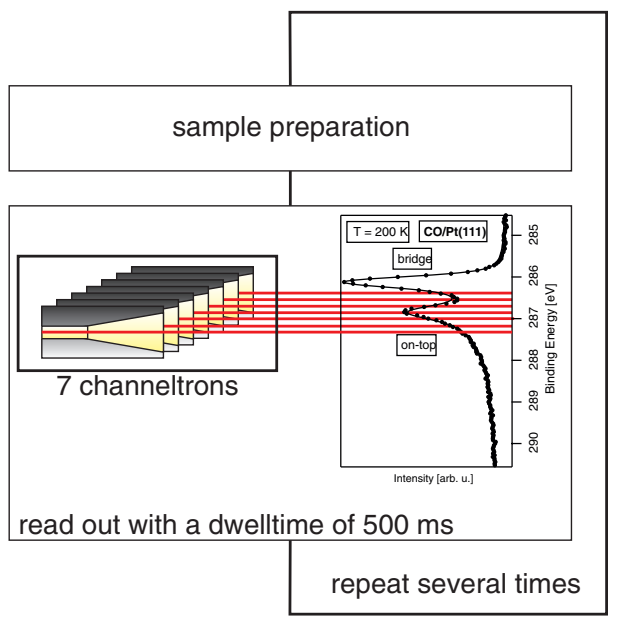

FIG. 1. (a) Conventional PES setup; one spectrum is measured completely with the swept mode, with a lower time resolution. (b) No shift in analyzer energy with gain in higher time resolution.

discuss the signal processing. In the original setup (also see Figure 2), the amplifiers of the 7 channeltrons in the analyzer generate an electric pulse for each electron detection event. This pulse is translated into optic signals and transferred by fiber optic cables (FOC) to a translator; there it is transformed to a TTL (transistor-transistor logic) signal, which is registered by a counter card. In the modified setup, we inserted a Y-switch after the translator that allows us to record the counts with another digital acquisition board (National Instruments, NI PCI6602) with 8 counting/pulsing channels. Seven of the eight channels are used to read out the channeltrons by tapping the TTL-signals at the Y-switch. The eighth channel gives the timer signal for synchronization of channel readouts. This process is controlled by a LabView program. The trigger for the dwell time, which determines the time resolution, is provided by a $2 \mathrm{kHz}$ signal from a signal generator (500 $\mu \mathrm{s} / \mathrm{channel}$ ); its rising edge triggers the readout of the channels to the onboard memory. The latter is copied to the main memory of the computer every $0.5 \mathrm{~s}$ in the background, while the counting of the TTL-signals continues. The LabView program also controls the opening and closing of the molecular beam shutter. 


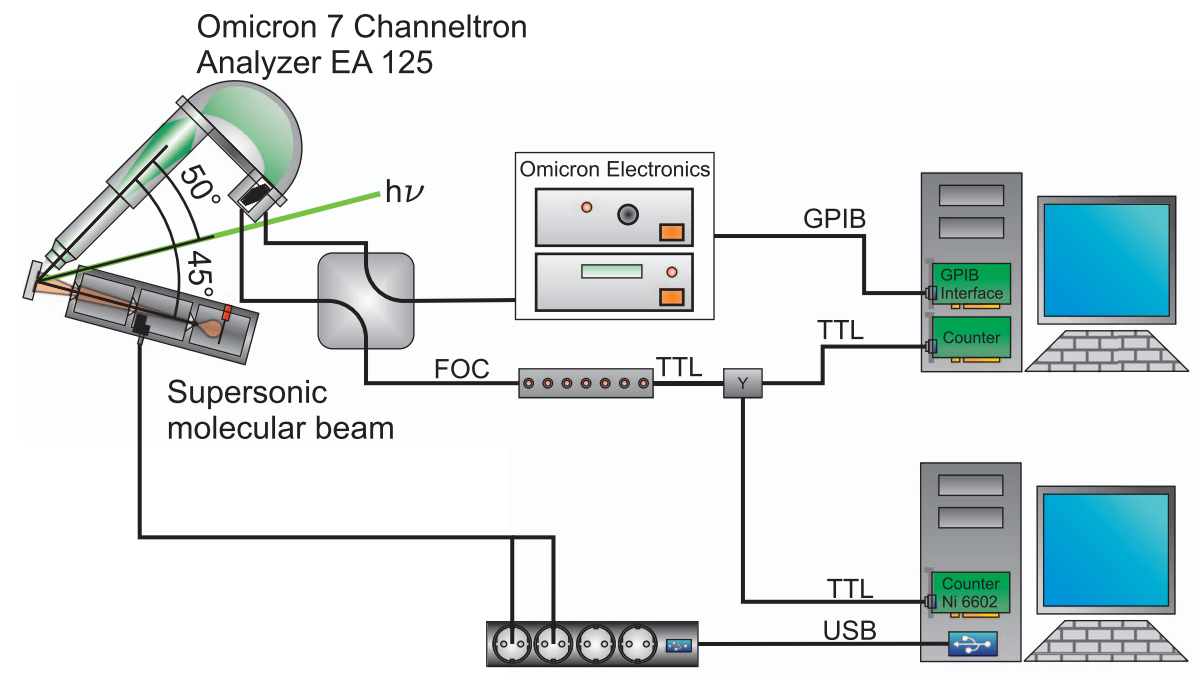

FIG. 2. Setup of the experiment and the added setup for fast XPS.

In Figure 3, a typical experiment, taken with this setup is shown. The data are recorded, while a $\mathrm{Pt}(111)$ surface at $460 \mathrm{~K}$ is exposed to the molecular beam for $7.5 \mathrm{~s}$. In order to achieve a sufficient signal to noise ratio, the experiment (which lasted $20 \mathrm{~s}$ ) was repeated 100 times, so that the total experiment lasted for $2000 \mathrm{~s}$ ( $\sim 33 \mathrm{~min})$. The data show the signal from one channeltron set to the binding energy of $\mathrm{CO}$ adsorbed at an on-top site (286.8 eV) vs. time (Figure 3(a)). At the starting time $(\mathrm{t}=0 \mathrm{~s})$, a constant background signal is observed. Upon opening the molecular beam at $\mathrm{t}=1.5 \mathrm{~s}$, the signals rapidly increase due to adsorption of $\mathrm{CO}$ at on-top and bridge sites, respectively. After $\sim 0.5 \mathrm{~s}$ (see Sec. III for details on the adsorption experiments) a plateau is reached, which corresponds to the equilibrium coverage at this given temperature and pressure (i.e., $\Theta=0.137 \mathrm{ML}$ at $\mathrm{T}=460$ $\mathrm{K}$ and $\left.\mathrm{p}=2 \times 10^{-6} \mathrm{mbar}\right)$. At $\mathrm{t}=9 \mathrm{~s}$, the shutter of the molecular beam is closed, leading to a rapid drop in intensity, due to the isothermal desorption of CO. After $11 \mathrm{~s}$, the signal has decreased to a value of below $2 \%$ of the maximum signal.

\section{MEASUREMENTS AND DATA ANALYSIS}

For an overview, we first briefly recapitulate the adsorption of CO on $\mathrm{Pt}(111)$ : In Figure 4(a), C 1 s XP spectra of the adsorption at a temperature of $200 \mathrm{~K}$ are shown up to a total coverage of $0.5 \mathrm{ML}$ (reproduced from Refs. 4 and 31), which displays a well ordered $c(4 \times 2)$ LEED pattern. The spectra show two peaks at 286.1 and $286.8 \mathrm{eV}$, due to $\mathrm{CO}$ adsorbed at bridge and on-top sites, respectively, with coverages of 0.25 ML each. The difference in the intensity of the two peaks is attributed to photoelectron diffraction effects. The binding energies of the two peaks show only minor changes with coverage $\left(\sim 0.07 \mathrm{eV}^{31}\right)$. Consequently, the occupation of a particular site can be measured by following the intensity at a particular (fixed) binding energy for this site (e.g., $286.8 \mathrm{eV}$ for the on-top site), rather than by acquiring a "full spectrum." The spectrum of the $c(4 \times 2)$ layer in Figure $4(b)$ served as a reference for the $\mathrm{CO}$ coverage calibration, e.g., for the $\mathrm{C}$ $1 s$ intensity in the equilibrium state in Figure 3 (plateau from
$2.5 \mathrm{~s}$ to $9 \mathrm{~s})$. During this experiment, the pressure of $\mathrm{CO}$ was $1.7 \times 10^{-9}$ mbar.

In Figure 5(a), C $1 s$ spectra measured under equilibrium conditions (i.e., with the molecular beam on) are shown, and Figure 5(b) depicts the corresponding equilibrium coverages vs. temperature. The data in the temperature range from 375 to $450 \mathrm{~K}$ were taken from Ref. 31 and the data from 460 to $500 \mathrm{~K}$ were obtained within this study. Overall, a strong temperature dependence of the equilibrium coverage is observed; the spectra for higher temperatures in Fig. 5(a) show that the population of the bridge adsorption site selectively decreases and at $500 \mathrm{~K}$ only the more stable on-top site is populated.

Next, we want to discuss the time-dependent adsorption and desorption behavior at temperatures from 460 to $500 \mathrm{~K}$ and compare them to previous data for lower temperatures taken from Ref. 30. The measurements between 460 and $500 \mathrm{~K}$ were performed using our new approach. A typical data set measured at $\mathrm{T}=460 \mathrm{~K}$ and $\mathrm{p}=2 \times 10^{-6}$ mbar is shown in Figure 3(a) with the channeltron set to the binding energy of the on-top site (286.8 eV) and in Figure 3(b) for the bridge site (286.1). The lower signal increase for the latter is due to its lower occupation (see Figure 4). Figure 3(c) shows the sum of the two signals as grey data, which reflect the total $\mathrm{CO}$ coverage. The data have been measured with $500 \mu \mathrm{s}$ per data point. As the characteristic time scales of the experiment are much slower, we can sum up 10 successive data points and thereby obtain a better signal to noise ratio, without a loss of information. The resulting curve (black data) then corresponds to data measured with $5 \mathrm{~ms}$ per data point. This signal will be used for the following analysis.

In Figures 6 and 7, we show the isothermal adsorption behavior (obtained from the data after switching on the CO beam) at temperatures between 460 and $490 \mathrm{~K}$, and the isothermal desorption behavior (obtained after switching off the $\mathrm{CO}$ beam) of $\mathrm{CO}$ on $\mathrm{Pt}(111)$ at temperatures between 375 and $500 \mathrm{~K}$; the denoted coverages represent total coverages. The data up to $450 \mathrm{~K}$ were measured with the standard swept approach, with 3-4 s per spectrum (cf. Figure 5(a)). At higher pressures and/or temperatures, this type of swept mode 

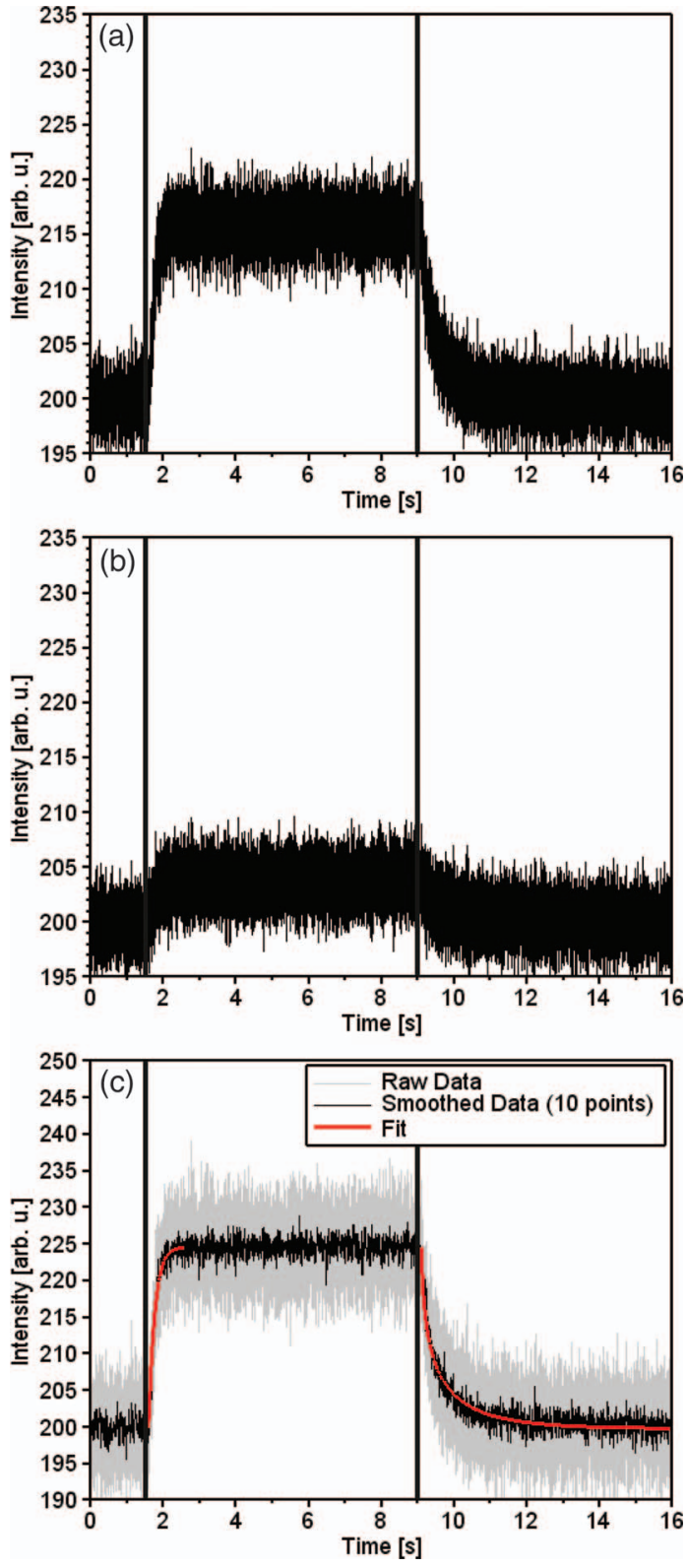

FIG. 3. (a) A complete measurement with a dwell time of $500 \mu$ s and 100 times repeated on the binding energy of the on-top position and (b) on the bridge energy position. (c) Light grey curve shows both channels from (a) and (b) added and scaled similar to Ref. 32. Lightest grey gives a time resolution of $500 \mu \mathrm{s}$. The darker grey gives $5 \mathrm{~ms}$ of time resolution. Black bars show the opening and closing of the molecular beam shutter. $\left(\Theta_{\mathrm{tot}}=0.14 \mathrm{ML}\right.$, $\mathrm{T}=460 \mathrm{~K}, \mathrm{p}_{\mathrm{CO}}=2 \times 10^{-6}$ mbar.)

measurements was not possible, due to the much faster characteristic time scales. This becomes evident from the adsorption measurements at $2 \times 10^{-6} \mathrm{mbar}$, where the equilibrium coverage is reached already after $\sim 0.3-0.4 \mathrm{~s}$ (see Figure 6 ) or from the desorption measurement at $500 \mathrm{~K}$, where more than $90 \%$ of the adsorbed molecules have desorbed within the first second (Figure 7(b)). The data above $450 \mathrm{~K}$ at pressures of $2 \times 10^{-6}$ mbar thus have been derived from measurements using our new approach, i.e., from experiments like that shown in Figure 3. Note that the higher pressure compared to the adsorption at $200 \mathrm{~K}$ was also necessary to achieve a higher equilibrium surface coverage. The denoted coverages again
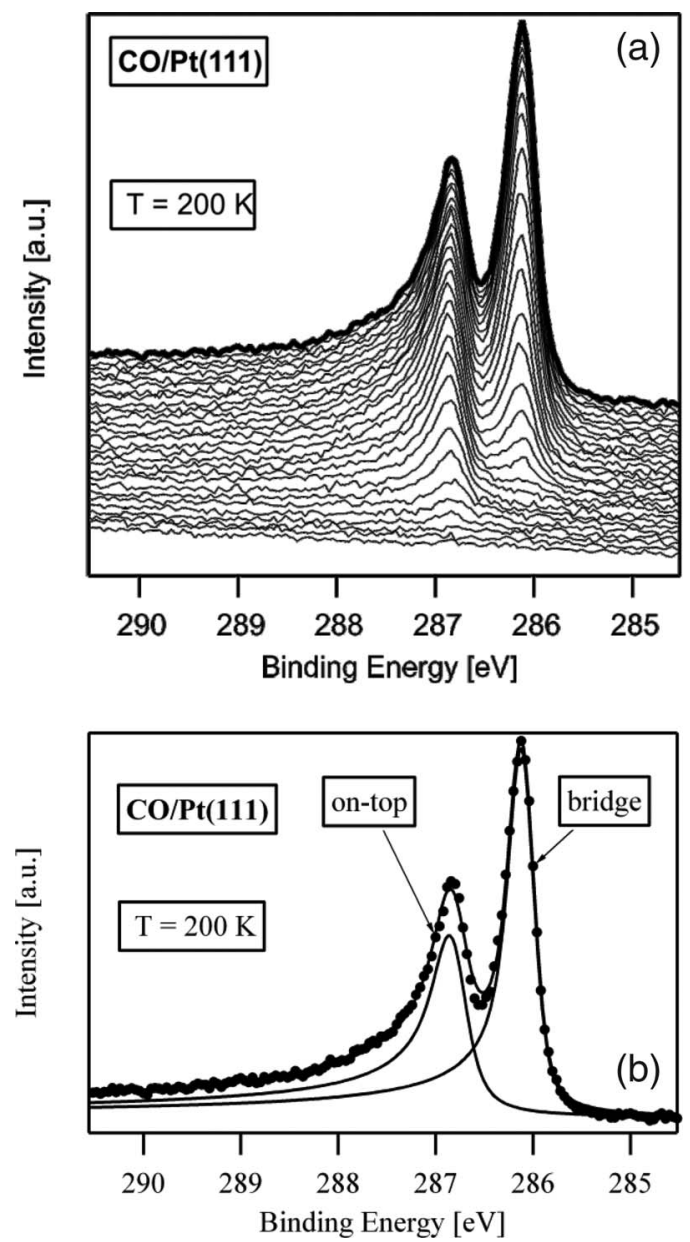

FIG. 4. (a) $\mathrm{C} 1 s$ spectra of the adsorption of $\mathrm{CO}$ at $200 \mathrm{~K}$ on $\mathrm{Pt}(111)$ according to Ref. $32\left(\mathrm{p}_{\mathrm{CO}}=1.7 \times 10^{-9}\right.$ mbar, every spectrum took $4.8 \mathrm{~s}, 60 \mathrm{~s}$ between each spectrum); (b) Fit of the saturated $\mathrm{C} 1 s$ spectrum, corresponding to the $\mathrm{c}(4 \times 2)$ superstructure of $\mathrm{CO}$ on $\operatorname{Pt}(111)(0.5 \mathrm{ML})$.

are the total coverages; they are derived by adding the signals for the on-top peak (at $286.8 \mathrm{eV}$ ) and the bridge peak (at $286.1 \mathrm{eV}$ ), obtained from two independent experiments. We want to point out that these experiments were done with a slightly higher photon flux of $17 \%$, showing no obvious photon induced effects in all experiments.

These data demonstrate that with our new approach we are indeed able to extend the accessible timescale for in situ adsorption and desorption experiments considerably, i.e., by a factor of 50-100 for the data presented here. In the next step, we now want to perform a simple analysis of both the existing data at the lower temperatures and pressures (Figure 7(a)) and the data obtained here (Figures 6 and 7(b)) with our new approach to check for consistency.

Before doing that, we introduce a simple model to describe adsorption and desorption of $\mathrm{CO}$ on $\mathrm{Pt}(111)$. Since the adsorption energy difference between the on-top site and the bridge site is very small $(40-90 \mathrm{meV}$, depending on the model ${ }^{4,32}$ ), site exchange between these two sites is in equilibrium. Considering that the adsorption energy, $E_{a}$, is much higher (e.g., $1.43 \mathrm{eV}$ according to Ref. 4) than this difference, one can treat the adsorption and desorption behavior at elevated temperatures, as studied here, by using an 

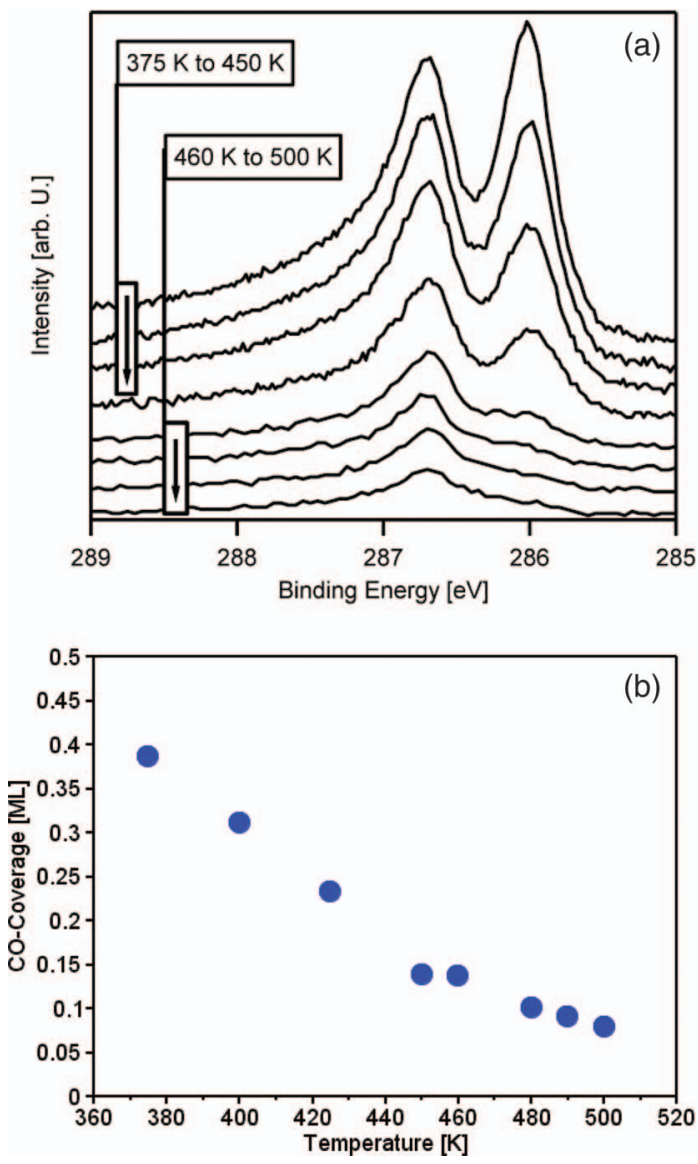

FIG. 5. (a) $\mathrm{C} 1 \mathrm{~s}$ spectra taken at the given temperatures between 375 and $500 \mathrm{~K}$ at a CO pressure of $2 \times 10^{-6}$ mbar. Data partly taken from Ref. 32 . (b) Coverage of $\mathrm{CO}$ on $\mathrm{Pt}(111)$ at different temperatures ( $\mathrm{p}_{\mathrm{CO}}=2 \times 10^{-6}$ mbar).

average adsorption energy (and also prefactor), as well as sticking coefficient. ${ }^{4,31}$ This certainly is a major simplification, but it allows us to check the data sets obtained under different conditions for consistency. Within this approach, the measured coverage change, $\dot{\Theta}$, can be described by coupled differential equations with a term for adsorption, $\dot{\Theta}_{a d}$, and desorption, $\dot{\Theta}_{d e s} 31,33$

$$
\dot{\Theta}=\dot{\Theta}_{a d}-\dot{\Theta}_{d e s}=j \cdot S(\Theta, T)-D \cdot \Theta .
$$

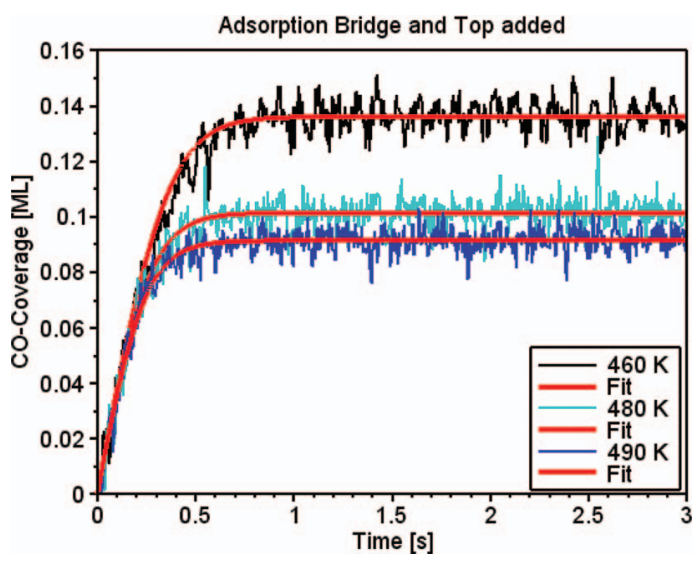

FIG. 6. Total coverage during the adsorption of $\mathrm{CO}$ on the $\mathrm{Pt}(111)$ surface at different temperatures. $\mathrm{p}_{\mathrm{CO}}=2 \times 10^{-6} \mathrm{mbar}$.
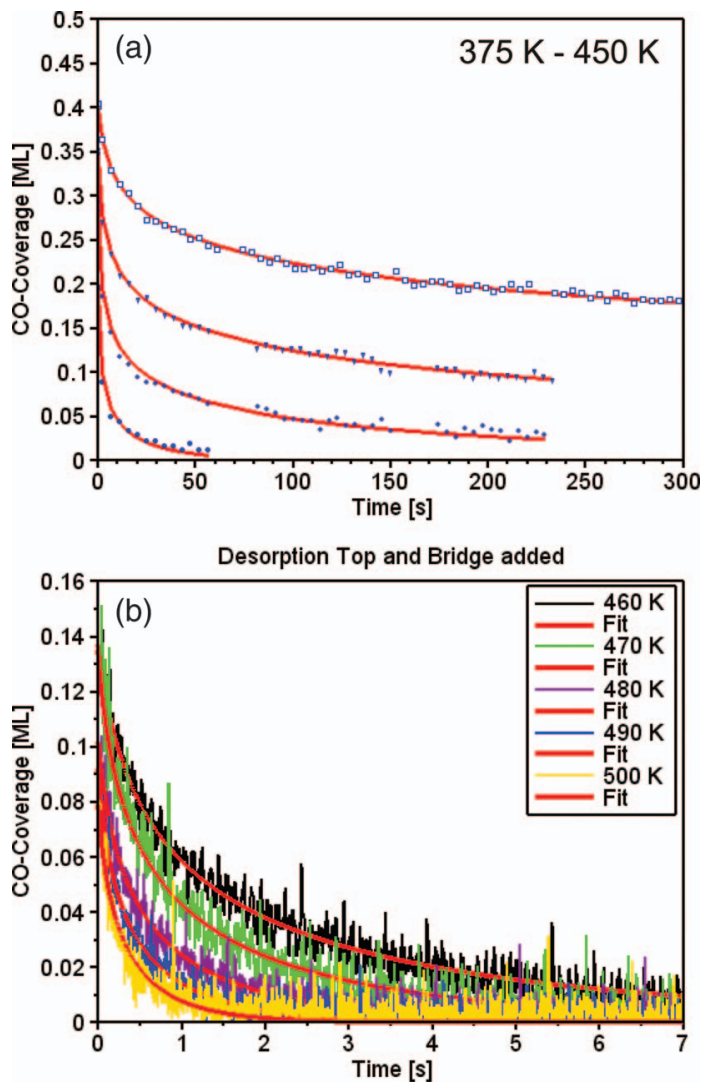

FIG. 7. Desorption of CO from the Pt(111) surface for different temperatures. The conventional method is shown in (a) (data taken from Ref. 32). In (b), the faster method is shown. $\mathrm{p}_{\mathrm{CO}}=2 \times 10^{-6} \mathrm{mbar}$.

$j$ is the molecule flux, $S(\Theta, T)$ is the coverage-dependent sticking coefficient, and $D$ the desorption constant. Strictly speaking, $S(\Theta, T)$ depends on the fractional coverages of bridge sites and on-top sites. However, since at a given temperature, the fractional coverages are precisely determined by the equilibrium between the two sites, the total coverage, $\Theta$, can be used without loss of information. Adsorption is commonly described with the Kisliuk model, which considers direct chemisorption on the bare surface and precursormediated adsorption on adsorbate-covered regions ${ }^{34}$ :

$$
S(\Theta, T)=S_{0}\left(1+K(T) \cdot \frac{\Theta}{\Theta_{\max }-\Theta}\right)^{-1} .
$$

Here, $S_{0}$ is the initial sticking coefficient, and the Kisliuk parameter, $K$, describes the ratio of the desorption and chemisorption rates from the physisorbed precursor. ${ }^{34}$ The desorption constant $D$ can be expressed with ${ }^{35}$ :

$$
D=D_{0}(T) \cdot \exp \left(-\frac{E_{a}(\Theta)}{k_{B} T}\right) .
$$

$D_{0}(T)$ is the preexponential factor and $k_{B}$ the Boltzmann constant. It has been shown by Kinne et al. ${ }^{4}$ that the adsorption energy $E_{a}$ linearly decreases with coverage

$$
E_{a}(\Theta)=E_{0}+E_{1} \cdot \Theta .
$$

Based on these considerations, the desorption behavior can be modeled, with the fit parameters $E_{0}, E_{1}$, and $D_{0}$, and the adsorption behavior with $j \cdot S_{0}, K$. 
For the fitting, the desorption behavior in Figures 6 and 7(b), we constrained the value for the adsorption energy $E_{0}$ to be $1.43 \mathrm{eV}$ and the coverage dependent term $E_{1}$ to be $-0.65 \mathrm{eV}$, i.e., to the values obtained by Kinne et al. ${ }^{4}$ for the low temperature data $(375-450 \mathrm{~K})$. Using these values, we obtain a consistent fit to the complete data set, i.e., also the data measured with the new approach for higher temperatures, the prefactor $D_{0}$ is in the range of $1 \times 10^{14.8 \pm 0.3} \mathrm{~s}^{-1}$. The fit results are indicated as red lines in the figures. The derived prefactor compares very well to the value of $2 \times 10^{15 \pm 1} \mathrm{~s}^{-1}$ determined by Kinne ${ }^{31}$ for the much smaller temperature range from 375 to $450 \mathrm{~K}$. The good agreement over the large temperature range is strong evidence for the reliability of the data obtained by our new approach and also shows that the intermolecular interaction $\left(\mathrm{E}_{2}\right)$ is not temperature dependent, at least in the simple model used here.

To describe the adsorption behavior, we fitted Eq. (1) with the constraint of a temperature independent value for $j \cdot S_{0}$, which is justified considering the small temperature interval from 460 to $490 \mathrm{~K}$; for $\mathrm{E}_{0}$ and $\mathrm{E}_{1}$ the values determined above (1.43 and $0.65 \mathrm{eV}$ ) were used and $\mathrm{D}_{0}$ was allowed to vary within the above denoted error bars. The Kisliuk parameters were determined as a function of temperature from earlier experiments, ${ }^{31}$ yielding $j \cdot S_{0}$ values of $0.80,0.84$, and 0.87 for the 460,480 , and $490 \mathrm{~K}$, respectively. The corresponding fit results, shown as red lines in Figure 6, are in excellent agreement with the experimental data.

Finally, we want to address the potential and limits of our new approach. The data in Figures 3(a) and 3(b) have been collected with a time resolution (dwell time) of $500 \mu \mathrm{s}$. From this experiment, we can extrapolate the smallest reasonable time resolution, i.e., dwell time. The count rate in this experiment is $\sim 400000$ counts/s $(\sim 200$ counts/s/channel in $500 \mu \mathrm{s}$ ), but with a higher photon flux or lower energy resolution count rates of up to 5 Mcounts/s are possible when using channeltrons (nonlinearity $<5 \%$; total deadtime incl. electronics: $70 \mathrm{~ns}$ ). With a reasonable number of counts per time step, which we propose to be $100 \mathrm{cts} / \mathrm{channel}$ (with the signal to be 10\%) and by an increase of the total measuring time by a factor of 2 (200 instead of 100 repetitions, yielding a total time for a complete experiment of $4000 \mathrm{~s}$ ), a factor of $\sim 25$ in time resolution can be gained. Thus from technical side, a time resolution of $\sim 20 \mu$ s appears feasible. Please note that if the signal is stronger (e.g., for metal adsorbates due to the much higher photoionization cross sections), even lower times might be possible.

\section{CONCLUSIONS}

To summarize, we have presented a new approach for ultrafast XPS to investigate surface processes. It is based on a conventional XPS setup with a channeltron-based electron energy analyzer and uses a modified signal processing unit, allowing for measurements in the $\mu$ s regime. First measurements with a time resolution of $500 \mu$ s allow to study the adsorption and desorption of $\mathrm{CO}$ on a $\operatorname{Pt}(111)$ surface at significantly higher temperatures and significantly higher pressures than were previously possible, i.e., up to $500 \mathrm{~K}$ and $2 \times 10^{-6}$ mbar. By comparing results obtained below $450 \mathrm{~K}$ by using the conventional XPS detection mode, i.e., the classical swept mode, to the results above $450 \mathrm{~K}$ obtained with our new approach, i.e., ultrafast measurements at a fixed energy, we demonstrated the reliability of this new technique. From a detailed analysis of the desorption data, we show that the simple assumption of a linear decrease of the adsorption energy with coverage leads to consistent results for the coverage range from 375 to $500 \mathrm{~K}$. From a critical evaluation of the experimental parameters and boundary conditions, we extrapolate that under favorable condition (i.e., high photoionization cross section of the investigated core levels and high photon flux) a time resolution of $20 \mu$ s or below seems feasible.

\section{ACKNOWLEDGMENTS}

The authors gratefully acknowledge the funding by the Cluster of Excellence "Engineering of Advanced Materials" (www.eam.uni-erlangen.de) at the University of ErlangenNürnberg and by the SFB 953 "Synthetic Carbon Allotropes". We thank HZB for the allocation of synchrotron radiation beamtime and their staff for support during beamtime, especially T. Kachel at U49/2 PGM-1.

${ }^{1}$ S. Yamamoto and I. Matsuda, J. Phys. Soc. Jpn. 82, 021003 (2013).

${ }^{2}$ D. N. Tafen, J. B. Miller, Ö. N. Dogan, J. P. Baltrus, and P. Kondratyuk, Surf. Sci. 608, 61 (2013).

${ }^{3}$ S. Ramakrishna and T. Seideman, J. Phys. B 45, 194012 (2012).

${ }^{4}$ M. Kinne, T. Fuhrmann, C. M. Whelan, J. F. Zhu, J. Pantförder, M. Probst, G. Held, R. Denecke, and H.-P. Steinrück, J. Phys. Chem. 117, 10852 (2002).

${ }^{5}$ R. Streber, C. Papp, M. P. A. Lorenz, A. Bayer, R. Denecke, and H.-P. Steinrück, Angew. Chem., Int. Ed. 48, 9743 (2009).

${ }^{6}$ K. Gotterbarm, N. Luckas, O. Höfert, M. P. A. Lorenz, R. Streber, C. Papp, F. Vines, H.-P. Steinrück, and A. Görling, J. Chem. Phys. 136, 094702 (2012).

${ }^{7}$ L. Gori, R. Tommasini, G. Cautero, D. Giuressi, M. Barnaba, A. Accardo, S. Carrato, and G. Paolucci, Nucl. Instrum. Methods Phys. Res. A 431, 338 (1999).

${ }^{8}$ D. P. Langstaff, A. Bushell, T. Chase, and D. A. Evans, Nucl. Instrum. Methods Phys. Res. B 238, 219 (2005).

${ }^{9}$ J.-M. Bussat, C. S. Fadley, B. A. Leudewigt, G. J. Meddeler, A. Nambu, M. Press, H. Spieler, B. Turko, M. West, and G. J. Zizka, IEEE Trans. Nucl. Sci. 51, 2341 (2004).

${ }^{10}$ R. Denecke, Appl. Phys. A 80, 977 (2005).

${ }^{11}$ I. Nakai, H. Kondoh, A. Resta, J. N. Andersen, T. Ohta, and T. Shimada, J. Chem. Phys. 124, 224712 (2006).

${ }^{12}$ F. Esch, A. Baraldi, C. Gomelli, S. Lizzit, and M. Kiskinova, J. Chem. Phys. 110, 4013 (1999).

${ }^{13}$ A. Baraldi, M. Barnaba, B. Brena, D. Cocco, G. Comelli, S. Lizzit, G. Paolucci, and R. Rosei, J. Electron Spectrosc. Relat. Phenom. 76, 145 (1995).

${ }^{14}$ A. Baraldi, G. Comelli, S. Lizzit, D. Cocco, G. Paolucci, and R. Rosei, Surf. Sci. Lett. 367, L67 (1996).

${ }^{15}$ A. Baraldi, J. Phys.: Condens. Matter 20, 093001 (2008).

${ }^{16}$ N. Luckas, K. Gotterbarm, R. Streber, M. P. A. Lorenz, O. Höfert, F. Vines, C. Papp, A. Görling, and H.-P. Steinrück, Phys. Chem. Chem. Phys. 13, 16227 (2011)

${ }^{17}$ S. Agnoli, T. Orzali, M. Sambi, J. Schoiswohl, S. Surnev, F. P. Netzer, and G. Granozzi, J. Electron Spectrosc. Relat. Phenom. 144-147, 465 (2005).

${ }^{18}$ A. Yoshigoe and Y. Teraoka, Appl. Surf. Sci. 190, 60 (2002).

${ }^{19}$ Y. Teraoka and A. Yoshigoe, Surf. Sci. 507-510, 797 (2002).

${ }^{20}$ W. Zhao, S. M. Kozlov, O. Höfert, K. Gotterbarm, M. P. A. Lorenz, F. Vines, C. Papp, A. Görling, and H.-P. Steinrück, J. Phys. Chem. Lett. 2, 759 (2011).

${ }^{21}$ S. Lizzit and A. Baraldi, Catal. Today 154, 68 (2010).

${ }^{22}$ L. Vattuone, L. Savio, M. Rocca, L. Rumiz, A. Baraldi, S. Lizzit, and G. Comelli, Phys. Rev. B 66, 085403 (2002). 
${ }^{23}$ C. M. Whelan, R. Neubauer, R. Denecke, and H.-P. Steinrück, Surf. Rev. Lett. 9, 789 (2002).

${ }^{24}$ C. M. Whelan, R. Neubauer, D. Borgmann, R. Denecke, and H.-P. Steinrück, J. Chem. Phys. 115, 8133 (2001).

${ }^{25}$ A. Stolow, A. E. Bragg, and D. M. Neumark, Chem. Rev. 104, 1719 (2004)

${ }^{26}$ M. Kamada, S. Tanaka, K. Takahashi, Y.-I. Doi, K. Fukui, T. Kinoshita, Y. Haruyama, S. Asaka, Y. Fujii, and M. Itoh, Nucl. Instrum. Methods Phys. Res. A 467-468, 1441 (2001)

${ }^{27}$ S. Tanaka, S. D. More, K. Takahashi, M. Kamada, T. Nishitani, and T. Nakanishi, Surf. Rev. Lett. 9, 1297 (2002).

${ }^{28}$ O. Hemmers, S. B. Whitfield, P. Glans, H. Wang, D. W. Lindle, R. Wehlitz, and I. A. Sellin, Rev. Sci. Instrum. 69, 3809 (1998).
${ }^{29}$ S. Tanaka, S. D. More, K. Takahashi, and M. Kamada, J. Phys. Soc. Jpn. 72, 659 (2003)

${ }^{30}$ R. Denecke, M. Kinne, C. M. Whelan, and H.-P. Steinrück, Surf. Rev. Lett. 9, 797 (2002).

${ }^{31}$ M. Kinne, Ph.D. thesis, Friedrich-Alexander-Universität ErlangenNürnberg, 2003

${ }^{32}$ J.-S. McEwen, S. H. Payne, J. J. Kreuzer, M. Kinne, R. Denecke, and H.-P. Steinrück, Surf. Sci. 545, 47 (2003).

${ }^{33}$ A. Cudok, H. Froitzheim, and M. Schulze, Phys. Rev. B 47, 13682 (1993).

${ }^{34}$ P. Kisliuk, J. Phys. Chem. Solids 3, 95 (1957).

${ }^{35}$ V. P. Zhdanov, Elementary Physicochemical Processes on Solid Surfaces (Plenum Press, 1991). 